\title{
Brain metastasis prognostic nomograms and brain metastasis velocity: a narrative review
}

\author{
Mohammed Abdulhaleem ${ }^{1}$, Jimmy Ruiz ${ }^{1}$, Christina Cramer ${ }^{2}$, Fei Xing ${ }^{1}$, Hui Wen Lo ${ }^{1}$, Jing Su ${ }^{1}$, \\ Michael D. Chan ${ }^{2}$ \\ ${ }^{1}$ Department of Internal Medicine, Wake Forest School of Medicine, Winston-Salem, NC, USA; ${ }^{2}$ Department of Radiation Oncology, Wake Forest \\ School of Medicine, Winston-Salem, NC, USA \\ Contributions: (I) Conception and design: M Abdulhaleem, J Ruiz, MD Chan; (II) Administrative support: MD Chan; (III) Provision of study \\ materials or patients: None; (IV) Collection and assembly of data: M Abdulhaleem, MD Chan; (V) Data analysis and interpretation: M Abdulhaleem, \\ MD Chan; (VI) Manuscript writing: All authors; (VII) Final approval of manuscript: All authors. \\ Correspondence to: Michael D. Chan, MD. Wake Forest School of Medicine, Winston-Salem, NC, USA. Email: mchan@wakehealth.edu.
}

Objective: To provide a review of the current status of predictive nomograms and brain metastasis velocity (BMV) in the prognostication of brain metastasis outcomes.

Background: Statistical analyses have been used for many years in an attempt to predict clinical outcomes of brain metastasis patients. Such models have attempted to predict such endpoints as survival and which patients would most benefit from stereotactic radiosurgery (SRS) or whole brain radiotherapy (WBRT).

Methods: This narrative review includes documents the history of statistical models and nomograms through the stage migration of the brain metastasis population from a population with large symptomatic brain metastases to the modern population with small asymptomatic metastases found on surveillance imaging. It also tells the history of the derivation and validation of BMV, a recently identified biomarker for survival and neurologic death in the brain metastasis population treated with SRS.

Conclusions: Statistical models predicting brain metastasis behavior continue to evolve with the changing landscape of systemic therapy and the more aggressive use of SRS. Previous models with ultimately need to integrate biologic data and will continue to be updated.

Keywords: Brain metastasis velocity (BMV); brain metastasis nomograms; stereotactic radiosurgery (SRS); whole brain radiation

Submitted Jul 29, 2021. Accepted for publication Oct 09, 2021.

doi: $10.21037 / \mathrm{cco}-21-102$

View this article at: https://dx.doi.org/10.21037/cco-21-102

\section{Introduction}

Recent randomized trials have demonstrated that stereotactic radiosurgery (SRS) has superior cognitive function over whole brain radiotherapy (WBRT) for patients with 4 or fewer brain metastases (1-3). Technology has also advanced such that treatment of more numerous lesions is technically feasible. Such advances as flattening filter free (FFF) linear accelerators, single isocenter multitarget (SIMT) radiosurgery, and stereotactic platforms that do not require rigid frame fixation have brought SRS into the community setting and made it more universally available and widely practiced (4).

As the ability to perform SRS has become ubiquitous, several issues have arisen in order to properly triage this resource. SRS is more technologically challenging to deliver, and therefore is more costly than a course of standard WBRT (5-7). Moreover, some patients will experience rapid development of numerous new brain metastases and therefore require WBRT soon after SRS - effectively wasting the efforts to spare cognition. In addition, there is a population of patients for which serial SRS is done in which cancer involves such a high volume of the brain that the likelihood of dying of neurologic death greatly rises (8). 
It is unclear as of yet whether upfront WBRT may be able to mitigate such risk, but current trials are investigating this possibility (9).

Because of the higher cost of SRS as a resource and because there are populations for which either upfront SRS or upfront WBRT may be a more optimal treatment option, there is an incentive to distinguish the patients who are most likely to benefit from upfront SRS from those most likely to benefit from upfront WBRT. Several attempts have been made to use statistical modeling to predict clinical outcomes for these patients in order to determine which upfront treatment strategy may be more optimal (SRS vs. WBRT). The goal of the present narrative review is to discuss the previous attempts to statistically model brain metastasis behavior and to assess their clinical utility. We present the following article in accordance with the Narrative Review reporting checklist (available at https:// cco.amegroups.com/article/view/10.21037/cco-21-102/rc).

\section{Methods}

Electronic search was conducted using the PubMed database. Search terms included brain metastasis nomograms and brain metastasis velocity (BMV). The search was restricted to studies published in the English language. The search included studies spanning the dates of January 1, 1997 to December 31, 2020.

\section{The heterogeneity of the brain metastasis population}

It has been known for some time now that clinical outcomes for the brain metastasis population are heterogeneous and often depend on the histology of the primary cancer from which the brain metastases originated. Such cytogenetic abnormalities as Her2 overexpression (10) and ALK (11) or EGFR mutations (12) can significantly improve the responsiveness of cancers to targeted therapy. Presence of these biomarkers can lead to longer survival and decreased likelihood of re-seeding the brain $(13,14) ;(12,15,16)$. In fact, even histological differences between subtypes of lung cancer can lead to differences in how commonly patients develop new brain metastases after SRS $(7,17)$.

A critical theme that appears to tie together the variation in brain metastasis clinical outcomes is the control of extracranial disease. If patients have a large burden of extracranial disease (18) or disease that is less responsive to therapy (19), they are more likely to have a poor prognosis.
As such, statistical models that would attempt to predict brain metastasis outcomes would be best derived by accounting for these factors.

There are also factors independent of control of extracranial disease that still affect brain metastasis outcomes. These factors include radioresistance, size and location of lesions within the brain, volume of brain metastases in the brain, as well as the propensity for hemorrhage. Radioresistance has been shown to worsen the likelihood of control of brain metastases and yield high rates of neurologic death when treated with conventionally fractionated whole brain radiation (20). SRS has been shown to have an improved local control in the radioresistant population (21).

As performance status has been demonstrated to be a critical determinant of survival for patients with brain metastases $(22,23)$, lesions located within eloquent portions of the brain may have an influence on patient outcomes such as survival. In addition, the cumulative volume of brain metastases can also affect patient outcomes by affecting patient neurocognitive status as well as the ability to successfully eradicate disease with radiotherapy (24).

\section{Patient subgroups that may benefit from upfront SRS}

The main reason patients benefit from SRS upfront is to avoid the cognitive sequelae of WBRT. The degree to which traditional WBRT can affect cognition can be quite dramatic as it is not unusual to have patient performance decline by a standard deviation or greater on cognitive testing within several months after WBRT completion $(1,25)$. The cognitive toxicity of WBRT may ultimately be mitigated by recent strategies of using a neuroprotective agent (memantine) (26) and using hippocampal avoidance techniques $(26,27)$. However, trials are presently being conducted comparing these strategies, and it may be several years before trials can determine whether these new strategies may preserve cognition as well as SRS does. The presently accruing CE7 study is randomizing patients with 5-15 brain metastases to SRS vs. hippocampal avoidance WBRT with memantine (28).

As WBRT is most commonly limited to a single application during the natural history of a patient's cancer, choosing the optimal time to deliver WBRT can be an important decision. While repeat WBRT has been reported, it by and large treats cancer to a lower dose than what is considered sufficient for long term control (29). 
It has been associated with poor survival outcomes (30). As such, postponing WBRT as long as possible with upfront SRS (with the intention of using WBRT only once during a patient's treatment) can be a strategic decision for many patients who do not have rapid multifocal brain failure.

\section{Patient subgroups that may benefit from upfront WBRT}

Patients that may benefit from upfront WBRT generally do so because either SRS has a high likelihood of missing subclinical disease or because the risk of SRS outweighs the toxicity of WBRT. Patients with numerous metastases may be more likely to benefit from WBRT as opposed to SRS. This is because with a greater number of metastases at time of diagnosis, there is a greater likelihood of there being radiographically occult disease that is not seen at time of SRS (31), and because as the cumulative volume irradiated with SRS rises, so does the risk of toxicity $(32,33)$. While the maximum number of metastases that are treatable is controversial, volume constraints can likely better elucidate the limitations of SRS. A contiguous V12 of greater than 8.5 cc yields a greater risk of radiation necrosis (32). If an SRS plan has a contiguous V12 that is significantly greater than this value or multiple individual volumes within the brain greater than this value, then the patient is likely at a high risk of significant toxicity from SRS. At present, there are several prospective trials being conducted assessing the role of SRS in patients with patients with maximum allowed brain metastases between 10 and 20 (4).

Patients with large and symptomatic brain metastases for which surgery is not feasible or appropriate may benefit from WBRT. The clinical response rate for patients with symptomatic brain metastases after WBRT is between $50 \%$ and $75 \%$ (34). Patients with symptomatic brain metastases that are left untreated have a median survival of 1-2 months $(35,36)$. Patients receiving WBRT for symptomatic brain metastases will be less likely to die of brain metastases than if they had gone untreated (37). The recently published QUARTZ study was a randomized trial comparing WBRT to supportive care for patients with brain metastases from non-small cell lung cancer that were unsuitable for surgery or SRS (38). While the trial showed no difference in survival, there was concern that many patients with poor performance status on this trial were enrolled, and that these patients would do poorly regardless of whether they had treatment for brain disease or not. While the trial was designed to include poor performance status patients, it would be more difficult to determine any benefit from WBRT in this population.

Small cell lung cancer has traditionally been a population thought to benefit from upfront WBRT (39), and even prophylactic cranial irradiation in patients who have not yet developed clear metastases (40-42). However, more recent data with upfront SRS alone suggests that some populations with small cell lung cancer (particularly if they have single or few lesions) may have equivalent outcomes to those treated with upfront WBRT (43). The NRG CC009 study is a presently open phase III trial comparing hippocampal avoidant WBRT with memantine to SRS for brain metastases from small cell lung cancer (44). This trial will likely determine the future upfront standard of care for patients with brain metastases from small cell lung cancer.

Patients with leptomeningeal dissemination represent a population that probably do not benefit from upfront SRS. This is due to the diffuse nature of the cancer spread along with meninges, the inability of imaging to predict the full extent of the disease, and the poor prognosis $(45,46)$. WBRT on the other hand has been shown to have a demonstrable benefit with regards to symptoms, though the ability to affect life expectancy is more controversial (47).

\section{Prognostic models for survival}

Life expectancy can be an important factor that may help to dictate the optimal treatment for a patient with brain metastases. For example, patients with short life expectancy and small asymptomatic lesions may not benefit from any CNS-directed therapy (38). Conversely, those with greater life expectancy may benefit more from aggressive use of SRS in order to postpone WBRT for as long as possible (48). Prognostic models for brain metastasis survival have been used for more than two decades. The brain metastasis population has evolved over that interval from being a population with predominantly larger symptomatic brain metastases to now being a population with smaller asymptomatic brain metastases diagnosed due to screening MRI's done at staging. As such, prognostic models have also evolved and have required updating to account for improved therapies and outcomes.

The first major prognostic index gaining widespread acceptance was the Radiation Therapy Oncology Group (RTOG) recursive partitioning analysis (RPA). The RPA represented an analysis of multiple RTOG prospective trials performed between 1979 and 1993, identifying 
performance status, age, and presence of extracranial disease as the dominant factors affecting survival (22). Over the next decade after the RPA was published, several additional prognostic indices were developed which also attempted to correlate predictive factors with survival. Each of these analyses found age, KPS and extracranial disease status to be important prognostic factors $(23,49,50)$. The score index for radiosurgery (SIR) also took into account the number and volume of largest metastases to indicate appropriateness for SRS (49). While these factors remain important in the modern setting, the predicted survival from these early prognostic indices has become obsolete given improving cancer treatments and the stage migration towards a modern population of small asymptomatic metastases.

The next major evolution for brain metastasis prognostic indices was the classification of metastases based on the primary cancer from which the metastases originated. Sperduto et al. performed a multi-institutional analysis of survival of 3,940 patients with newly diagnosed brain metastases, grouping them by the primary cancer (51). This analysis produced the diagnosis-specific graded prognostic assessment (ds-GPA). This ds-GPA has since been updated to include molecular markers in lung cancer such as EGFR and ALK (52), as well as estrogen/progesterone and HER2 status for breast cancer (53).

\section{Nomograms for distant brain failure and salvage WBRT}

A recent cost analysis of brain metastasis management in the USA found that the determination of management strategy between upfront SRS and upfront WBRT was the single most significant factor that affects the cost of brain metastasis management over a patient's lifetime (7). This is clearly a difficult issue as cost effectiveness of treatments will depend on the insurance system from each country. However, identifying the population who require early WBRT salvage would be meaningful not only clinically, but also with regards to resource utilization. In general, these patients represent the population who experience rapid development of numerous new brain metastases (54). Several attempts have been made to predict distant brain failure. Ayala-Peacock published a nomogram predicting the incidence of distant brain failure after upfront SRS and found that systemic disease status, number of metastases and histology were dominant factors that affected the rate of distant brain failure (18). Press et al. created a nomogram that was predictive of distant brain failure and salvage
WBRT and found that number of metastases, smaller lesion volume and melanoma or breast histology to be important risk factors (55). Gorovets et al. created a nomogram that was predictive of survival without salvage WBRT finding extracranial disease burden, symptom burden and number of metastases to be significant predictive factors (56).

While the aforementioned nomograms have potential for impacting clinical management, several issues with nomogram application in the brain metastasis population have been identified. These concerns include the heterogeneity of the brain metastasis population and the fact that systemic cancer treatment continues to evolve and improve. As such, predictive models need validation with independent datasets. A validation study of two nomograms that predicted distant brain failure showed that attempts with independent validation from a mixed academic and community population demonstrated limited predictive ability from either nomogram with the independent dataset (57). Ayala-Peacock et al. recently updated a nomogram for distant brain failure that was validated by data from 9 academic centers (58). A summary of brain metastasis predictive nomograms is seen in Table 1. The presently accruing CCTG CE7 study will be attempting to prospectively validate this nomogram in the patients randomized to the SRS arm (28).

Even with validation, however, models that predict clinical outcomes can quickly become obsolete with the advent of a novel systemic therapy that significantly changes control of extracranial disease. This phenomenon was seen first with the advent of targeted agents $(13,21)$, and then also with the wide adoption of immunotherapy (59). A likely future direction will be to have a continually updated repository for brain metastasis outcomes, as well as predictive models based on genomic biomarkers.

\section{BMV}

Farris et al. recently identified BMV as a biomarker that predicted overall survival and likelihood of dying from neurologic death (60). BMV is defined as the number of new brain metastases diagnosed since upfront SRS (not including those treated at the first SRS) divided by the time since SRS. The resulting value represents the rate at which new cancer is seeding the brain, and is representative of the degree of control of systemic cancer. BMV has been validated by multiple subsequent studies including from North America, Japan and Europe (61-63). A summary of available series that have validated BMV is shown in Table 2. 
Table 1 Predictive nomograms for brain metastasis outcomes

\begin{tabular}{|c|c|c|c|c|}
\hline Author, year/predictive model & $\begin{array}{l}\text { No. of } \\
\text { patient }\end{array}$ & $\begin{array}{l}\text { What the model } \\
\text { predicted }\end{array}$ & Major predictive factors & $\begin{array}{l}\text { Validation } \\
\text { (internal/external) }\end{array}$ \\
\hline Gaspar et al., 1997: RPA (22) & 1,200 & OS & $\begin{array}{l}\text { Performance status, age, presence of extracranial } \\
\text { metastasis, primary tumor }\end{array}$ & External \\
\hline Weltman et al., 2000: SIR (49) & 65 & OS & $\begin{array}{l}\text { Age, performance status, extracranial disease status, } \\
\text { number and volume of brain lesions }\end{array}$ & Internal \\
\hline $\begin{array}{l}\text { Ayala-Peacock et al., 2014: Wake } \\
\text { Forest DBF Nomogram (18) }\end{array}$ & 464 & DBF & $\begin{array}{l}\text { Primary diagnosis, number of brain metastasis, } \\
\text { widespread/progression of systemic disease }\end{array}$ & Internal \\
\hline $\begin{array}{l}\text { Press et al., 2015: Emory DBF } \\
\text { Nomogram (55) }\end{array}$ & 270 & $\begin{array}{l}\text { DBF/time to } \\
\text { WBRT }\end{array}$ & $\begin{array}{l}\text { Primary diagnosis, number of and volume of brain } \\
\text { metastasis, previous WBRT }\end{array}$ & External \\
\hline $\begin{array}{l}\text { Ayala-Peacock, } 2017 \text { : } \\
\text { USA/Canada DBF Nomogram (58) }\end{array}$ & 1,354 & DBF/BMV & $\begin{array}{l}\text { Age, sex, primary tumor type, largest tumor size, } \\
\text { number of brain metastases }\end{array}$ & External \\
\hline
\end{tabular}

RPA, recursive partitioning analysis; SIR, score index for radiosurgery; ds-GPA, diagnosis-specific graded prognostic assessment; OS, overall survival; DBF, distant brain metastasis; WBRT, whole brain radiotherapy; BMV, brain metastasis velocity.

Table 2 Series on brain metastasis velocity

\begin{tabular}{|c|c|c|c|c|c|}
\hline Author, year/Institution & $\begin{array}{l}\text { Total number of } \\
\text { patients with upfront } \\
\text { SRS without WBRT }\end{array}$ & $\begin{array}{l}\text { Number of patients } \\
\text { with DBF after initial } \\
\text { SRS }\end{array}$ & $\begin{array}{l}\text { Low risk BMV } \\
\text { mOS (months) } \\
\qquad(95 \% \mathrm{Cl})\end{array}$ & $\begin{array}{c}\text { Intermediate risk } \\
\text { BMV mOS (months) } \\
(95 \% \mathrm{Cl})\end{array}$ & $\begin{array}{l}\text { High risk BMV } \\
\text { mOS (months) } \\
(95 \% \mathrm{Cl})\end{array}$ \\
\hline $\begin{array}{l}\text { Yamamoto et al., 2019/Tokyo } \\
\text { Women's Medical University Center } \\
\text { East, Japan (63) }\end{array}$ & 3,424 & 833 & $12.9(10.2-17.7)$ & $7.5(6.5-9)$ & $5.1(4.0-5.6)$ \\
\hline $\begin{array}{l}\text { McTyre et al., 2020/USA/Canada } \\
\text { (62) }\end{array}$ & 2,092 & 786 & $12.5(11.0-14.8)$ & $7.0(5.9-9.4)$ & $4.6(3.8-5.3)$ \\
\hline $\begin{array}{l}\text { Fritz et al., 2018/University Hospital } \\
\text { Zurich, Switzerland (61) }\end{array}$ & 42 & NA & 23 & 19 & 10 (combined) \\
\hline
\end{tabular}

SRS, stereotactic radiosurgery; WBRT, whole brain radiotherapy; DBF, distant brain failure; BMV, brain metastasis velocity; mOS, median overall survival; $\mathrm{Cl}$, confidence interval; $\mathrm{NA}$, not available.

The proposed utility of BMV has been to help to triage patients to the proper salvage regimen after distant brain failure from SRS. Those patients with low BMV ( $<4$ metastases/year) likely benefit from further SRS at time of distant brain failure. Those with high BMV ( $>13$ metastases/year) have a shorter life expectancy and are more likely to die from brain metastases. The ongoing NRG BN009 study is randomizing patients with intermediate or high BMV to repeat SRS vs. repeat SRS with adjuvant hippocampal avoidant WBRT in order to determine whether adding WBRT can treat subclinical disease sufficiently to decrease the likelihood of future death from brain metastases.

BMV's application as a potential biomarker continues to evolve. BMV has also been suggested as a marker for the efficacy of systemic therapy in preventing new brain metastases (9). Initial BMV (iBMV) has been recently described as a marker for how quickly brain metastases 
develop from the time of initial cancer diagnosis (64). iBMV may represent the biological predilection that a cancer subtype or an individual cancer may have on seeding the brain. Several studies have since attempted to validate iBMV's utility (65-67). Presently, there are ongoing efforts to correlate genomic markers to both $\mathrm{BMV}$ and $\mathrm{iBMV}$ $(68,69)$. One particularly important advancement in BMV will be to assess a disease-specific BMV to determine whether the histology of the brain metastasis affects the effect of BMV on survival.

\section{Conclusions}

Statistical models to predict brain metastasis outcomes have long contributed to clinical management decisions and have been integrated into modern prospective trials. As the brain metastasis population and systemic treatments evolve, these models will require continual updating. Future directions likely involve prospective gathering of multi-institutional data in order to better facilitate the evolution of these models, as well as integration of molecular biomarkers.

\section{Acknowledgments}

Funding: None.

\section{Footnote}

Provenance and Peer Review: This article was commissioned by the Guest Editors (Simon S. Lo, Balamurugan Vellayappan, Kevin Shiue and Jonathan P. S. Knisely) for the series "The Modern Approaches to the Management of Brain Metastases" published in Chinese Clinical Oncology. The article has undergone external peer review.

Reporting Checklist: The authors have completed the Narrative Review reporting checklist. Available at https:// cco.amegroups.com/article/view/10.21037/cco-21-102/rc

Conflicts of Interest: All authors have completed the ICMJE uniform disclosure form (available at https://cco.amegroups. com/article/view/10.21037/cco-21-102/coif). The series "The Modern Approaches to the Management of Brain Metastases" was commissioned by the editorial office without any funding or sponsorship. The authors have no other conflicts of interest to declare.

Ethical Statement: The authors are accountable for all aspects of the work in ensuring that questions related to the accuracy or integrity of any part of the work are appropriately investigated and resolved.

Open Access Statement: This is an Open Access article distributed in accordance with the Creative Commons Attribution-NonCommercial-NoDerivs 4.0 International License (CC BY-NC-ND 4.0), which permits the noncommercial replication and distribution of the article with the strict proviso that no changes or edits are made and the original work is properly cited (including links to both the formal publication through the relevant DOI and the license). See: https://creativecommons.org/licenses/by-nc-nd/4.0/.

\section{References}

1. Brown PD, Jaeckle K, Ballman KV, et al. Effect of Radiosurgery Alone vs. Radiosurgery With Whole Brain Radiation Therapy on Cognitive Function in Patients With 1 to 3 Brain Metastases: A Randomized Clinical Trial. JAMA 2016;316:401-9.

2. Aoyama H, Shirato H, Tago M, et al. Stereotactic radiosurgery plus whole-brain radiation therapy vs. stereotactic radiosurgery alone for treatment of brain metastases: a randomized controlled trial. JAMA 2006;295:2483-91.

3. Kocher M, Soffietti R, Abacioglu U, et al. Adjuvant wholebrain radiotherapy versus observation after radiosurgery or surgical resection of one to three cerebral metastases: results of the EORTC 22952-26001 study. J Clin Oncol 2011;29:134-41.

4. Soike MH, Hughes RT, Farris M, et al. Does Stereotactic Radiosurgery Have a Role in the Management of Patients Presenting With 4 or More Brain Metastases? Neurosurgery 2019;84:558-66.

5. Lester SC, Taksler GB, Kuremsky JG, et al. Clinical and economic outcomes of patients with brain metastases based on symptoms: an argument for routine brain screening of those treated with upfront radiosurgery. Cancer 2014;120:433-41.

6. Lal LS, Byfield SD, Chang EL, et al. Cost-effectiveness analysis of a randomized study comparing radiosurgery with radiosurgery and whole brain radiation therapy in patients with 1 to 3 brain metastases. Am J Clin Oncol 2012;35:45-50.

7. Shenker RF, McTyre ER, Taksler GB, et al. Analysis of the drivers of cost of management when patients with brain metastases are treated with upfront radiosurgery. Clin 
Neurol Neurosurg 2019;176:10-4.

8. McTyre ER, Johnson AG, Ruiz J, et al. Predictors of neurologic and nonneurologic death in patients with brain metastasis initially treated with upfront stereotactic radiosurgery without whole-brain radiation therapy. Neuro Oncol 2017;19:558-66.

9. LeCompte MC, Hughes RT, Farris M, et al. Impact of brain metastasis velocity on neurologic death for brain metastasis patients experiencing distant brain failure after initial stereotactic radiosurgery. J Neurooncol 2020;146:285-92.

10. Perez EA, Romond EH, Suman VJ, et al. Updated results of the combined analysis of NCCTG N9831 and NSABP B-31 adjuvant chemotherapy with/without trastuzumab in patients with HER2-positive breast cancer. J Clin Oncol 2007;25:512.

11. Kwak EL, Bang YJ, Camidge DR, et al. Anaplastic lymphoma kinase inhibition in non-small-cell lung cancer. N Engl J Med 2010;363:1693-703.

12. Lynch TJ, Bell DW, Sordella R, et al. Activating mutations in the epidermal growth factor receptor underlying responsiveness of non-small-cell lung cancer to gefitinib. N Engl J Med 2004;350:2129-39.

13. Johnson AG, Ruiz J, Hughes R, et al. Impact of systemic targeted agents on the clinical outcomes of patients with brain metastases. Oncotarget 2015;6:18945-55.

14. Vern-Gross TZ, Lawrence JA, Case LD, et al. Breast cancer subtype affects patterns of failure of brain metastases after treatment with stereotactic radiosurgery. J Neurooncol 2012;110:381-8.

15. Johung KL, Yeh N, Desai NB, et al. Extended Survival and Prognostic Factors for Patients With ALK-Rearranged Non-Small-Cell Lung Cancer and Brain Metastasis. J Clin Oncol 2016;34:123-9.

16. Magnuson WJ, Lester-Coll NH, Wu AJ, et al. Management of Brain Metastases in Tyrosine Kinase Inhibitor-Naïve Epidermal Growth Factor ReceptorMutant Non-Small-Cell Lung Cancer: A Retrospective Multi-Institutional Analysis. J Clin Oncol 2017;35:1070-7.

17. Kuremsky JG, Urbanic JJ, Petty WJ, et al. Tumor histology predicts patterns of failure and survival in patients with brain metastases from lung cancer treated with gamma knife radiosurgery. Neurosurgery 2013;73:641-7; discussion 647.

18. Ayala-Peacock DN, Peiffer AM, Lucas JT, et al. A nomogram for predicting distant brain failure in patients treated with gamma knife stereotactic radiosurgery without whole brain radiotherapy. Neuro Oncol 2014;16:1283-8.
19. Lanier CM, McTyre E, LeCompte M, et al. The number of prior lines of systemic therapy as a prognostic factor for patients with brain metastases treated with stereotactic radiosurgery: Results of a large single institution retrospective analysis. Clin Neurol Neurosurg 2018;165:24-8.

20. Wrónski M, Maor MH, Davis BJ, et al. External radiation of brain metastases from renal carcinoma: a retrospective study of 119 patients from the M. D. Anderson Cancer Center. Int J Radiat Oncol Biol Phys 1997;37:753-9.

21. Cochran DC, Chan MD, Aklilu M, et al. The effect of targeted agents on outcomes in patients with brain metastases from renal cell carcinoma treated with Gamma Knife surgery. J Neurosurg 2012;116:978-83.

22. Gaspar L, Scott C, Rotman M, et al. Recursive partitioning analysis (RPA) of prognostic factors in three Radiation Therapy Oncology Group (RTOG) brain metastases trials. Int J Radiat Oncol Biol Phys 1997;37:745-51.

23. Sperduto CM, Watanabe Y, Mullan J, et al. A validation study of a new prognostic index for patients with brain metastases: the Graded Prognostic Assessment. J Neurosurg 2008;109 Suppl:87-9.

24. Routman DM, Bian SX, Diao K, et al. The growing importance of lesion volume as a prognostic factor in patients with multiple brain metastases treated with stereotactic radiosurgery. Cancer Med 2018;7:757-64.

25. Chang EL, Wefel JS, Hess KR, et al. Neurocognition in patients with brain metastases treated with radiosurgery or radiosurgery plus whole-brain irradiation: a randomised controlled trial. Lancet Oncol 2009;10:1037-44.

26. Brown PD, Pugh S, Laack NN, et al. Memantine for the prevention of cognitive dysfunction in patients receiving whole-brain radiotherapy: a randomized, double-blind, placebo-controlled trial. Neuro Oncol 2013;15:1429-37.

27. Brown PD, Gondi V, Pugh S, et al. Hippocampal Avoidance During Whole-Brain Radiotherapy Plus Memantine for Patients With Brain Metastases: Phase III Trial NRG Oncology CC001. J Clin Oncol 2020;38:1019-29.

28. Roberge D, Brown PD, Whitton A, et al. The Future Is Now-Prospective Study of Radiosurgery for More Than 4 Brain Metastases to Start in 2018! Front Oncol 2018;8:380.

29. Wong WW, Schild SE, Sawyer TE, et al. Analysis of outcome in patients reirradiated for brain metastases. Int $\mathrm{J}$ Radiat Oncol Biol Phys 1996;34:585-590.

30. Guo S, Balagamwala EH, Reddy C, et al. Clinical and Radiographic Outcomes From Repeat Whole- 
brain Radiation Therapy for Brain Metastases in the Age of Stereotactic Radiosurgery. Am J Clin Oncol 2016;39:288-93.

31. Loganathan AG, Chan MD, Alphonse N, et al. Clinical outcomes of brain metastases treated with Gamma Knife radiosurgery with $3.0 \mathrm{~T}$ versus $1.5 \mathrm{~T}$ MRI-based treatment planning: have we finally optimised detection of occult brain metastases? J Med Imaging Radiat Oncol 2012;56:554-60.

32. Minniti G, Clarke E, Lanzetta G, et al. Stereotactic radiosurgery for brain metastases: analysis of outcome and risk of brain radionecrosis. Radiat Oncol 2011;6:48.

33. Ohtakara K, Hayashi S, Nakayama N, et al. Significance of target location relative to the depth from the brain surface and high-dose irradiated volume in the development of brain radionecrosis after micromultileaf collimatorbased stereotactic radiosurgery for brain metastases. J Neurooncol 2012;108:201-9.

34. McTyre E, Scott J, Chinnaiyan P. Whole brain radiotherapy for brain metastasis. Surg Neurol Int 2013;4:S236-44.

35. Ruderman NB, Hall TC. Use of glucocorticoids in the palliative treatment of metastatic brain tumors. Cancer 1965;18:298-306.

36. Markesbery WR, Brooks WH, Gupta GD, et al. Treatment for patients with cerebral metastases. Arch Neurol 1978;35:754-6.

37. Lagerwaard FJ, Levendag PC, Nowak PJ, et al. Identification of prognostic factors in patients with brain metastases: a review of 1292 patients. Int J Radiat Oncol Biol Phys 1999;43:795-803.

38. Mulvenna P, Nankivell M, Barton R, et al. Dexamethasone and supportive care with or without whole brain radiotherapy in treating patients with nonsmall cell lung cancer with brain metastases unsuitable for resection or stereotactic radiotherapy (QUARTZ): results from a phase 3 , non-inferiority, randomised trial. Lancet 2016;388:2004-14.

39. Harris S, Chan MD, Lovato JF, et al. Gamma knife stereotactic radiosurgery as salvage therapy after failure of whole-brain radiotherapy in patients with small-cell lung cancer. Int J Radiat Oncol Biol Phys 2012;83:e53-9.

40. Aupérin A, Arriagada R, Pignon JP, et al. Prophylactic cranial irradiation for patients with small-cell lung cancer in complete remission. Prophylactic Cranial Irradiation Overview Collaborative Group. N Engl J Med 1999;341:476-84.

41. Slotman B, Faivre-Finn C, Kramer G, et al. Prophylactic cranial irradiation in extensive small-cell lung cancer. $\mathrm{N}$ Engl J Med 2007;357:664-72.

42. Farris MK, Wheless WH, Hughes RT, et al. LimitedStage Small Cell Lung Cancer: Is Prophylactic Cranial Irradiation Necessary? Pract Radiat Oncol 2019;9:e599-607.

43. Rusthoven CG, Yamamoto M, Bernhardt D, et al. Evaluation of First-line Radiosurgery vs. WholeBrain Radiotherapy for Small Cell Lung Cancer Brain Metastases: The FIRE-SCLC Cohort Study. JAMA Oncol 2020;6:1028-37.

44. Pereira I, Slotman B, Rusthoven CG, et al. Stereotactic radiosurgery (SRS) - A new normal for small cell lung cancer? Clin Transl Radiat Oncol 2020;25:10-5.

45. Huang AJ, Huang KE, Page BR, et al. Risk factors for leptomeningeal carcinomatosis in patients with brain metastases who have previously undergone stereotactic radiosurgery. J Neurooncol 2014;120:163-9.

46. Vincent A, Lesser G, Brown D, et al. Prolonged regression of metastatic leptomeningeal breast cancer that has failed conventional therapy: a case report and review of the literature. J Breast Cancer 2013;16:122-6.

47. Wasserstrom WR, Glass JP, Posner JB. Diagnosis and treatment of leptomeningeal metastases from solid tumors: experience with 90 patients. Cancer 1982;49:759-72.

48. Greene-Schloesser D, Robbins ME, Peiffer AM, et al. Radiation-induced brain injury: A review. Front Oncol 2012;2:73.

49. Weltman E, Salvajoli JV, Brandt RA, et al. Radiosurgery for brain metastases: a score index for predicting prognosis. Int J Radiat Oncol Biol Phys 2000;46:1155-61.

50. Lorenzoni J, Devriendt D, Massager N, et al. Radiosurgery for treatment of brain metastases: estimation of patient eligibility using three stratification systems. Int J Radiat Oncol Biol Phys 2004;60:218-24.

51. Sperduto PW, Kased N, Roberge D, et al. Summary report on the graded prognostic assessment: an accurate and facile diagnosis-specific tool to estimate survival for patients with brain metastases. J Clin Oncol 2012;30:419-25.

52. Sperduto PW, Yang TJ, Beal K, et al. Estimating Survival in Patients With Lung Cancer and Brain Metastases: An Update of the Graded Prognostic Assessment for Lung Cancer Using Molecular Markers (Lung-molGPA). JAMA Oncol 2017;3:827-31.

53. Sperduto PW, Kased N, Roberge D, et al. Effect of tumor subtype on survival and the graded prognostic assessment for patients with breast cancer and brain metastases. Int J Radiat Oncol Biol Phys 2012;82:2111-7. 
54. Mc'Tyre E, Ayala-Peacock D, Contessa J, et al. Multiinstitutional competing risks analysis of distant brain failure and salvage patterns after upfront radiosurgery without whole brain radiotherapy for brain metastasis. Ann Oncol 2018;29:497-503.

55. Press RH, Prabhu RS, Nickleach DC, et al. Novel risk stratification score for predicting early distant brain failure and salvage whole-brain radiotherapy after stereotactic radiosurgery for brain metastases. Cancer 2015;121:3836-43.

56. Gorovets D, Ayala-Peacock D, Tybor DJ, et al. Multiinstitutional Nomogram Predicting Survival Free From Salvage Whole Brain Radiation After Radiosurgery in Patients With Brain Metastases. Int J Radiat Oncol Biol Phys 2017;97:246-53.

57. Prabhu RS, Press RH, Boselli DM, et al. External validity of two nomograms for predicting distant brain failure after radiosurgery for brain metastases in a biinstitutional independent patient cohort. J Neurooncol 2018;137:147-54.

58. Ayala-Peacock DN, Attia A, Braunstein SE, et al. Prediction of new brain metastases after radiosurgery: validation and analysis of performance of a multiinstitutional nomogram. J Neurooncol 2017;135:403-11.

59. Lanier CM, Hughes R, Ahmed T, et al. Immunotherapy is associated with improved survival and decreased neurologic death after SRS for brain metastases from lung and melanoma primaries. Neurooncol Pract 2019;6:402-9.

60. Farris M, McTyre ER, Cramer CK, et al. Brain Metastasis Velocity: A Novel Prognostic Metric Predictive of Overall Survival and Freedom From Whole-Brain Radiation Therapy After Distant Brain Failure Following Upfront Radiosurgery Alone. Int J Radiat Oncol Biol Phys 2017;98:131-41.

61. Fritz C, Borsky K, Stark LS, et al. Repeated Courses of Radiosurgery for New Brain Metastases to Defer Whole

Cite this article as: Abdulhaleem M, Ruiz J, Cramer C, Xing F, Lo HW, Su J, Chan MD. Brain metastasis prognostic nomograms and brain metastasis velocity: a narrative review. Chin Clin Oncol 2022;11(2):10. doi: 10.21037/cco-21-102
Brain Radiotherapy: Feasibility and Outcome With Validation of the New Prognostic Metric Brain Metastasis Velocity. Front Oncol 2018;8:551.

62. McTyre ER, Soike MH, Farris M, et al. Multi-institutional validation of brain metastasis velocity, a recently defined predictor of outcomes following stereotactic radiosurgery. Radiother Oncol 2020;142:168-74.

63. Yamamoto M, Aiyama H, Koiso T, et al. Validity of a Recently Proposed Prognostic Grading Index, Brain Metastasis Velocity, for Patients With Brain Metastasis Undergoing Multiple Radiosurgical Procedures. Int J Radiat Oncol Biol Phys 2019;103:631-7.

64. Soike MH, McTyre ER, Hughes RT, et al. Initial brain metastasis velocity: does the rate at which cancers first seed the brain affect outcomes? J Neurooncol 2018;139:461-7.

65. Yamamoto M, Serizawa T, Nagano O, et al. Threeinstitution study on applicability of initial brain metastasis velocity for breast cancer brain metastasis patients undergoing stereotactic radiosurgery. J Neurooncol 2020;147:177-84.

66. Yamamoto M, Aiyama H, Koiso T, et al. Applicability and limitations of a recently-proposed prognostic grading metric, initial brain metastasis velocity, for brain metastasis patients undergoing stereotactic radiosurgery. J Neurooncol 2019;143:613-21.

67. Ho JW, Aznar-Garcia L. High Initial Brain Metastasis Velocity Is Associated With Shorter Brain Progression Free Survival After Stereotactic Radiosurgery For Brain Metastases. Int J Radiat Oncol Biol Phys 2020;108:E713.

68. Dohm A, Su J, McTyre ER, et al. Identification of CD37, cystatin A, and IL-23A gene expression in association with brain metastasis: analysis of a prospective trial. Int J Biol Markers 2019;34:90-7.

69. Su J, Song Q, Qasem S, et al. Multi-Omics Analysis of Brain Metastasis Outcomes Following Craniotomy. Front Oncol 2021;10:615472. 